\title{
Grundtvig-litteratur 1971-1973
}

\author{
Ved Aage Jørgensen
}

Nedenstående bibliografi over Grundtvig-litteraturen 1971-1973 er at betragte som en videreførelse af tilsvarende bibliografier ved hhv. Aage Jørgensen og Karen Højer-Pedersen offentliggjort i Grundtvig-Studier 1968, s. 76-85, og 1971 , s. $107-10$.

Stoffet er ordnet efter bibliografiske kriterier frem for efter emnekredse. Tidsrammen gælder ikke absolut, idet enkelte bidrag af ældre dato og adskillige fra begyndelsen af året 1974 er medtaget.

Iøvrigt er at bemærke, at bibliografien ikke medtager afhandlinger etc., som er fremkommet i Grundtvig-Studier. Undtagelser fra reglen er nogle anmeldelser, som naturligt føjer sig ind i på anden vis etablerede sammenhænge.

Med hensyn til avisstoffet gælder, at bibliografien ikke gør krav på fuldstændighed. Medtaget er i alt væsentligt, hvad også Avis Kronik Index har fundet det rimeligt at redde fra glemsel.

\section{Udgaver}

Grundtvig og det folkelige. Tekstudvalg ved Marianne Juhl Christiansen og Lise Ettrup. Studieserien udgivet af Dansklærerforeningen. Gyldendal, København 1972. 47 s. [Heri 6 Grundtvig-tekster, samt 7 tekster af andre danske forfattere.]

Tre Danne-Virke-artikler. Akademisk Boghandel, Århus 1972. 47 s. (Tekster til undervisningsbrug, 5.) [Indhold: "Om dansk Poesie, Sprog og Historie* (Danne-Virke I 1816, s. 16-35); „Om Ordsprog « (Danne-Virke III 1817, s. 62-88); "Om Digterne Baggesen og Oehlenschläger* (Danne-Virke IV 1819 , s. 195-233). Teksterne er optrykt fotografisk efter Varker $i$ Udvalg, II, 1941, s. 161-70, 195-208 og 220-40.]

Velkommen igen, Guds engle små. Med originalgrafik af Henry Heerup. Brøndums Forlag, København 1972. 27 upag. s. [Forord af Ejvind Larsen s. 5-10.] Anmeldt af: Leo Estvad (Berlingske Aftenavis 23. 12. 1971).

\section{Separattrykte Afhandlinger}

Ehnevid, Tord, Församlingsetik. Studier över Grundtvig, Morten Pontoppidan och Einar Billing. C. W. K. Gleerup, Lund 1969. 360 s. (Studia Theologica Lundensia, 29.) [Akad. avh.; engelsk resumé s. 329-41.]

Anmeldt af: P. G. Lindhardt (Grundtvig-Studier 1971, s. 111-12), N. H. Søe (Kristeligt Dagblad 15. 12. 1969). 
Elbek, Jørgen, Grundtvigs atten prøveår. GMT, Grenå 1973. $40 \mathrm{~s}$.

Anmeldt af :Poul Engberg (Kristeligt Dagblad 5.3.1974). Cf. Poul Behrendt, "Portræt af en kritiker - $\mathrm{i}$ anledning af Jørgen Elbeks sidste bog « (Kritik nr. 31, 1974, s. 41-51).

Harbsmeier, Götz, Wer ist der Mensch? Grundtvigs Beitrag zur humanen Existenz. Alternativen zu Kierkegaard. Vandenhoeck \& Ruprecht, Göttingen 1972. 245 s. (Kontroverse um Kierkegaard und Grundtvig, 3.)

Anmeldt af: Aage Jørgensen (Tidens Skole LXXVI 1974, s. 58-59, Flensborg Avis 5. 4. 1973, Kristeligt Dagblad 7. 6. 1973), Viggo Mortensen (Information 12. 2. 1973), A. Pontoppidan Thyssen (Dansk teologisk Tidsskrift XXXVI 1973, s. 313-15), Hellmut Toftdahl (Grundtvig-Studier 1973, s. 215-17). Cf. Per Lønning, »Fra Kierkegaard til Grundtvig - og retur«, Tidsskrift for teologi og kirke 1973, s. 61-62.

Larsen, Ejvind, Grundtvig - og noget om Marx. Studenterkredsen, Ārhus 1974. 86 s. [Bogen er samtidig nr. 4 af 40 . årg., 1972 (!), af medlemsbladet Kredsen.]

Anmeldt af: Poul Engberg (Kristeligt Dagblad 21.3. 1974), Hans-Jørgen Nielsen (Information 12. 3. 1974). Cf. Ebbe Kløvedal Reich, "Marx, troen og kultureliten« (Politiken 18. 3. 1974), samt Kaj Thaning, "Grundtvig og Marx « (Dansk Udsyn LIV 1974, s. 186-208).

Nauman, St. Elmo H., Jr., The Social Philosophies of Søren Kierkegaard and Nikolai Frederik Severin Grundtvig. 224 s. [Ph. D.-thesis, Boston University Graduate School, 1969; cf. Dissertation Abstracts XXX A, s. 2081-82.]

Nielsen, Jens A., Grundtvig og grev Danneskiold. Et bidrag til Gisselfelds kulturhistorie. [Jean Petersens Bogtrykkeri.] Haslev 1972. 33 s. [Med tegninger af Bent Schmidt. - Oprindelig trykt i Haslev Seminariums elevforening. Arsskrift 1971, s. 9-18.]

Reich, Ebbe Kløvedal, Frederik. En folkebog om N. F. S. Grundtvigs tid og liv. Billedredaktion: Ole Kragh. Gyldendal, København 1972. 402 s.

Anmeldt af: Gustav Albeck (Grundtvig-Studier 1972, s. 65-69), H. C. Borup (Holbak Amts Venstreblad 25. 3. 1972), Thomas Bredsdorff (Politiken 24. 3. 1972), Bris. [0: E. Chr. Bernhardsen] (B. T. 24. 3. 1972), Jakob Busk (Ringkjøbing Amts Dagblad 28. 3. 1972), Poul Engberg (Kristeligt Dagblad 1. 4. 1972), Emil Frederiksen (Berlingske Tidende 24.3. 1972), Hans Holmberg (Frederiksborg Amts Avis 24.3.1972), Jørgen Bonde Jensen (Vindrosen $\mathrm{XIX}: 2$ 1972, s. 105-12), Kr. Jespersen (Sjallands Tidende 24. 3. 1972), Jens Kruuse (Jyllands-Posten 24. 3. 1972), Ejvind Larsen (Information 24. 3. 1972), Palle Lauring (Ekstrabladet 28. 3. 1972), P. G. Lindhardt (Højskolebladet 1972, s. 280-83), Henrik Neiiendam (Weekendavisen 24. 3. 1972), Arne Fog Petersen (Dagbladet 24.3.1972), Ole Hyltoft Petersen (Aktuelt 24. 3. 1972), K. Rønne (Dansk Kirketidende CXXIV 1972, s. 383), Johannes Sløk (Aarhuus Stiftstidende 24. 3. 1972). - Cf. S. Borella-Hansen, „Grundtvig lever i bedste velgående«, Frederiksborg Amts Avis 19.5. 1972; Niels Thomsen, "Ebbe og Frederik«, Information 12.5.1972 (om »en afgørende forskel « mellem forf. og hans hovedperson). - Cf. også Johs. H. Christensens og Viggo Mortensens artikler ndf. u. IV, samt Reichs artikel i 
Ekstrabladet 24.3.1972. - Interviews med Reich i anledning af bogens udgivelse: Helle Nissen (Frederiksborg Amts Avis 25. 3. 1972), Ole Hyltoft Petersen (Aktuelt 25. 3. 1972), Kjeld Rask Therkilsen (Berlingske Tidende 19. 3. 1972).

Thaning, Kaj, For menneskelivets skyld. Grundtvigs opgør med sig selv. Gyldendal, København 1971. 223 s.

Anmeldt af: Erik Skøtt Andersen (Aktuelt 31.1.1972), Poul Engberg (Kristeligt Dagblad 17.11.1971), Tage Eskestad (Ringkjøbing Amts Dagblad 20.11. 1971; Vejle Amts Folkeblad 3. 12. 1971), Knud Hansen (Dansk Udsyn LII 1972, s. 66-72; Kirke og Kultur LXXVII 1972, s. 433-36), Peter Kemp (Politiken 20.11.1971), Ebbe Reich Kløvedal (Information 16.12.1971), P. G. Lindhardt (Jyllands-Posten 16.11. 1971), Paul Heide Ottosen (Højskolebladet 1972, s. 612-15).

Thaning, Kaj, N. F. S. Grundtvig. Translated from the Danish by David Hohnen. Det danske Selskab, København 1972. 180 s., 16 pl. [Også udsendt i tysk og fransk oversættelse.]

Anmeldt af: P. G. Lindhardt (Jyllands-Posten 15. 11. 1972), Viggo Mortensen (Information 12. 2. 1973), Erik Jensen og Børge Roesen (Aalborg Stiftstidende 18. 1. 1973), David Isitt (Scandinavica XIII 1974, s. 152-53).

\section{Afsnit i litteraturhistoriske o.a. Fremstillinger}

Beyer, Edvard, »Grundtvig«. I: Verdens Litteratur Historie. Under redaktion af F. J. Billeskov Jansen, Hakon Stangerup og P. H. Traustedt. VII: Romantikken, 1800-1830. Politiken, København 1972, s. 143-46.

Brask, Peter, Tekst og tolkning. Bidrag til den litterære semantik. Første del: Tekstbeskrivelsens teori og metode. I-II [med fortløbende paginering]. RUC Boghandel og Forlag, Roskilde 1974, s. 356-98 (om indledningen til „Paaskeliljen«, samt »småbemærkninger« om andre Grundtvig-digte), 481-98 (om »Som Dugg paa slagne Enge«).

Brøndsted, Mogens, "Danmark [1800-1830]«. I: Nordens Litteratur. [I:] For 1860. Redigeret af Mogens Brøndsted. Gyldendal, København / Gyldendal, Oslo / C. W. K. Gleerup, Lund 1972, s. 267-83. Cf. reg. i bd. [II], s. 583.

Dansk historisk Bibliografi 1913-1942. Udgivet af Den danske historiske Forening ved Henry Bruun. IV: Personalhistorie, almindelig Del og speciel Del, $A-J$. Rosenkilde \& Bagger, København 1970, s. 319-39 (o: numrene 3645936866).

Germer, Peter, Ytringsfrihedens vasen. Juristforbundets Forlag, København 1973 , s. 12-17. [Om den grundlovgivende rigsforsamlings af Grundtvig stærkt prægede debat om grundlovens trykkefrihedsparagraf.]

Henriksen, Aage, Organismetanken - en hovedlinje i det 19. århundredes tankning og digtning. Studieserien udgivet af Dansklærerforeningen. Gyldendal, København 1973, s. 39-41.

Jensen, Th. Borup, »N. F. S. Grundtvig«. I: Salmen som lovsang og litteratur. Under redaktion af Th. Borup Jensen og K. E. Bugge. II. Gyldendal, København 1972, s. 133-70. [Analyser af "I Kveld blev der banket« (s. 133-46). 
»At sige Verden ret Farvel« (s. 147-56) og »O Christelighed« (s. 157-69); cf. reg., også til bd. I.]

Klem, Lone \& Erling Nielsen, Navne $i$ dansk litteratur. 2. reviderede og forøgede udgave. Gyldendal, København 1970, s. 60-63, hvortil 4 pl. ml. s. 40 og 41. [Supplementsbind til Gyldendals Bibliotek; 1. udgave, 1963.]

L[oesch], L[ise], "Grundtvig, N. F. S.«. I: Henning Harmer \& Thomas Jørgensen (red.), Gyldendals litteraturleksikon. II: F-J. Gyldendal, København 1974 , s. $103-06$.

Malling, Anders, Dansk Salme Historie. VI: Digterne A-K. J. H. Schultz, København 1971, s. 221-66.

Mitchell, P. M., A History of Danish Literature. 2. forøgede udgave. KrausThomson Organization Ltd., New York 1971, s. 126-34 (๖: kapitlet »Grundtvig «). Cf. reg.

Mortensen, Finn Hauberg, Litteraturfunktion og symbolnorm 1800-1870. Kunstsynet fra romantik til naturalisme belyst ud fra opfattelsen af symbol- og billedsprog $i$ samtidens danske litteraturkritik. I-II [med fortløbende paginering]. Akademisk Forlag, København 1973, s. 189-223 (ग: kapitlet ^N. F. S. Grundtvig«). Cf. reg. s. 644.

Møller, Per Stig, Erotismen. Den romantiske bevagelse i Vesteuropa 1790-1860. Munksgaard, København 1973, s. 110-14. Cf. reg.

Paul, Fritz, Henrich Steffens. Naturphilosophie und Universalromantik. Wilhelm Fink Verlag, München 1973, s. 204-08. Cf. reg. [Habilitationsschrift.]

Rørdam, Thomas, The Danish Folk High School. [Translated by Sigurd Mammen.] Det danske Selskab in cooperation with Foreningen for Højskoler og Landbrugsskoler, Copenhagen 1965. Spec. s. 9-15 (0: kapitlet "Grundtvig's Ideas for a Folk High School«).

Troels-Lund, [T.], Bakkehus og Solbjerg. Trak af et nyt livssyns udvikling i Norden. 2. udgave [ved Hans Hartvig Seedorff]. II. Gyldendal, København 1972, s. 39-89 (ग: kapitlet »Nicolai Frederik Severin Grundtvig«). Cf. reg.

\section{Artikler i Tidsskrifter og Samlevarker}

Arnholtz, Arthur, „Grundtvigs salmer og deres melodier. Foredrag ved Grundtvig-Selskabets årsmøde 20. oktober 1950«. I: Vers og sang. Festskrift til Arthur Arnholtz 28. 11. 1971. Akademisk Forlag, København 1971, s. 108-39. [Fotografisk optryk efter Grundtvig-Studier 1952, s. 7-38.]

Belding, Robert E., »One European High School - Lessons for New Nations? * Journal of Secondary Education XLIII 1967-68, s. 88-92.

Borup, N. H., »Ritual og salme hos Grundtvig«. Dansk Kirketidende CXXII 1970, s. 137-40. [Om Christian Thodbergs En glemt dimension etc., 1969.]

Bukdahl, Jørgen, »Eros og Agape. Et Grundtvigportræt«. I hans: Folkelighed og eksistens. Gyldendal, København 1971, s. 84-123. [Oprindelig trykt i Dansk Udsyn XLIV 1964, s. 214-44.]

Bogen anmeldt af bl. a.: Knud Hansen (Hojskolebladet 1971, s. 760-63, 765) og Holger Kjær (Dansk Udsyn LII 1972, s. 61-66).

Bukdahl, Jørgen, »Grundtvig, Kold og højskolen«. Dansk Kirketidende CXXIV 1972, s. 88-90, 104-07. 
Christensen, Johs. H., "Froderik in excelsis (I-II)«. Prasteforeningens Blad LXII 1972, s. 561-69, 697-706, 713-20. [Om Kaj Thanings For menneskelivets skyld og Ebbe Kløvedal Reichs Frederik; se hertil: Kaj Thaning, „Falske alternativer", smst. LXIII 1973, s. 277-84.]

Christensen, Johs. H., »Om at anskaffe sig meninger og om at omgås dem«. Vartovbogen 1973, s. 161-76.

Christensen, Marie, »Grundtvig og 1864«. Dansk Kirketidende CXVI 1964, s. 159-61.

Christensen, Marie, »Ydre Mission og Grundtvig«. Dansk Kirketidende CXVIII 1966 , s. $445-48$.

Egebak, Niels, „De Levendes Land«. I: Kritiske tekster. III: Impressionistisk/ nykritisk/strukturalistisk. Ved Mette Winge og Uffe Andreasen. Gyldendal, København 1972, s. 55-69. [Optrykt efter Oluf Bohn (red.), Fra modernisme til ny-marxistisk kritik (cf. Grundtvig-Studier 1971, s. 109); også trykt i Grundtvig-Studier 1970, s. 67-77.]

Elbek, Jørgen, "Fra Grundtvigs ungdom«. Dansk Kirketidende CXXIV 1972, s. 544-48, 557-59, 570-73. [Foredrag holdt ved Kirkeligt Samfunds årsmøde i Vartov 17. 10. 1972.]

Elbek, Jørgen, "Fra Grundtvigs ventetid«. Dansk Kirketidende CXXV 1973, s. 236-39, 248-51.

Elbek, Jørgen, „Omkring 'Nyårsmorgen'«. Dansk Kirketidende CXXV 1973, s. 332-34, 346-49, 358-62.

Elbek, Jørgen, »Fra Nyårsmorgen til Nordens Mytologi. Et tillæg til 'Grundtvigs atten prøveår' «. Kritik nr. 31, 1974, s. 35-40.

Engberg, Poul, »Den genopdagede Grundtvig«. Kirkens Verden XIV 1972, s. 209-16.

Eskelund, Lotte, »Grundtvig. Poet, Prophet und Umgestalter«. Dänische Rundschau nr. 42, 1973, s. 29-31.

Glahn, Henrik, »Om melodierne til 'Alt står i Guds faderhånd'«. Dansk Kirkesangs årsskrift 1969-70, 1971, s. 63-74.

Grue-Sørensen, K., [Anmeldelse af Knud Eyvin Bugge (udg.), Grundtvigs skoleverden i tekster og udkast, I-II.] Arbog for dansk skolehistorie 1969, s. 126-27. [Anmeldelsen er identisk med den i Grundtvig-Studier 1968, s. 76, fortegnede.]

Hansen, Steffen Birk, "Grundtvigs 'Saga' og Danmarks Saga«. Kredsen XLI 1973 , s. $45-62$.

Hansen, Uffe, »Brage-Snak«. Højskolebladet 1972, s. 778-79.

Hansen, Uffe, "Helligåndssalmer«. Dansk Kirketidende CXVIII 1966, s. 201-03, 209-12, 221-23, 232-34.

Hansen, Uffe, "Grundtvig og alterbogen, I: Om religion og liturgi, 1806; II. Grundtvigs 'frisprog' «. Dansk Kirketidende CXXIII 1971, s. 14-15, 59-61.

Harbsmeier, Götz, "Kierkegaard und Grundtvig«. I: Sören Kierkegaard. Herausgegeben von Heinz-Horst Schrey. Wissenschaftliche Buchgesellschaft, Darmstadt 1971, s. 385-99. [Oprindelig trykt i Evangelische Theologie XXV 1965, s. 72 i3; også optrykt i Kontroverse um Kierkegaard und Grundtvig, I, 1966.] 
Heinemeier, Erik, "Grundtvigs påskeforkyndelse i salmerne«. Dansk Kirketidende CXVI 1964, s. 179-82.

Høirup, Henning, "Af: Fra Døden til Livet«. I: Kritiske tekster. II: Biografisk/ eksistentialistisk/idéhistorisk. Ved Mette Winge og Uffe Andreasen. Gyldendal, København 1972, s. 70-86. [Optrykt efter forf.'s Fra Døden til Livet. Grundtvigs tanker om liv og død, 1954, s. 11-26.]

Haarder, Bertel, »Grundtvigs frisyn [frihedssyn?] «. Dansk Kirketidende CXXII 1970, s. 415-18, 428-30, 450-51, og CXXIII 1970, s. 139-42, 153-55.

Jepsen, Holger, "Hvad er aktuelt hos Grundtvig?«Vartovbogen 1973, s. 64-75.

Jespersen, Aage, "Grundtvig og den lutherske kaldstanke«. Dansk Kirketidende CXVII 1965, s. 51-56, 63-70.

Jespersen, Aage, „Grundtvigs forkyndelse over Den Store Nadver«. Dansk Kirketidende CXVII 1965, s. 245-48, 253-56, 261-64.

Kabell, Aage, »Modersmaalet«. Danske Studier 1974, s. 5-17, spec. s. 14-17.

Kristensen, Jørgen, "Grundtvig på frisisk«. Hymnologiske Meddelelser II 1973, s. $77-80$.

Kristensen, Jørgen \& Jens Lyster, »Grundtvigsalmer på tysk«. Hymnologiske Meddelelser I:2, dec. 1971, s. 3-7. [Om salmeoversættelser af Werner Görnandt og Jørgen Kristensen/Götz Harbsmeier.]

Lindhardt, P. G., »Til belysning af Grundtvigs Englands-rejse 1843«. Kirkehistoriske Samlinger 1972, s. 97-156. [Med 17 breve fra Nugent Wade til Grundtvig og 2 fra William Palmer til Grundtvig.]

Lindhardt, P. G., "Død i 100 år, men -«. Dansk Udsyn LII 1972, s. 346-66.

Lund-Sørensen, A., "'Kun ved badet og ved bordet'«. Dansk Kirketidende CXVI 1964, s. 275-78.

Mortensen, Viggo, »Om at gøre Grundtvig levende. En kritisk stillingtagen til nogle nyere Grundtvig-tolkninger «. Kirke og Kultur LXXVII 1972, s. 42(132; Vartovbogen 1972, s. 91-107. [Især om Ejvind Larsens forord til Velkommen igen, Guds engle små og Ebbe Kløvedal Reichs Frederik.]

Münster, Knud, »Bevidstgørelse og gode vibrationer. Studenterkredsens sommermøde på Krabbesholm 31/7-4/8 [1972]«. Studenterkredsen XL 1972, s. 3236. [Referat af mødet, der afsluttedes med et Grundtvig-seminar. - Et lidt mere udførligt referat fremkom i Dansk Kirketidende CXXIV 1972, s. 380$82,391-94,416-18$.

Nielsen, E. Brandt, "Grundtvig og det levende ord «. Dansk Kirketidende CXVI 1964, s. 11-15, 35-37, 49-52, 63-66, 123-26. [Rettelse s. 67.]

Nielsen, E. Brandt, »Om Grundtvig og det donatistiske problem«. Dansk Kirketidende CXVII 1965, s. 31-35.

Nielsen, E. Brandt, "Var og forblev Grundtvig romantiker? « Dansk Kirketidende CXVII 1965, s. 85-88.

Nielsen, E. Brandt, »Grundtvig og myterne«. Dansk Kirketidende CXIX 1967, s. $366-68,373-76,381-84$.

Nielsen, Johs. Birkedal, »Om fremmedgørelse og hjemkærlighed«. Vartovbogen 1971, s. 7-14.

Nyholm, Paul C., [I:] »Grundtvig og [James] Montgomery«; [II]: »Morgen i Maj«. Dansk Kirketidende CXXII 1970, s. 59-62, 170-73. 
Paludan, Otto, »Om fremadvendt Lutherdom hos Grundtvig«. Dansk Kirketidende CXVI 1964, s. 337-40. [Om Kaj Thanings Menneske forst etc., 1963; hertil svar af K. T. smst. s. 347-48, med gensvar af O. P. s. 366-67.]

Prenter, Regin, »Betydningen af Grundtvigs folkelige tanker i dag«. Dansk Kirketidende CXXIV 1972, s. 508-11, 521-25. [Foredrag holdt ved Kirkeligt Samfunds årsmøde i Vartov 17. 10. 1972.]

Prenter, Regin, »Grundtvig i dag«. Ribe Stiftsbog 1973, s. 7-13.

$\mathrm{R}$ [iemann], $\mathrm{P}$ [eter], »Videnskab om at være menneske«. Dansk Kirketidende CXVI 1964, s. 260-62, 269-71. [Anmeldelse af Kaj Thanings Menneske forst etc., 1963.]

R[iemann], P[eter], "Lindhardts Grundtvig«. Dansk Kirketidende CXVII 1965,

s. 78-80. [Anmeldelse af P. G. Lindhardts Grundtvig, 1964.]

Riemann, Peter, "Grundtvig og Morten Luther«. Dansk Kirketidende CXIX 1967, s. 393-97. [Referat af foredrag holdt ved Kirkeligt Samfunds egnsmøde i Struer 18. 10. 1967.]

Riishøj, Axel, »Grundtvig og samfundet«. Vartovbogen 1971, s. 15-32.

Rømhild, Lars Peter, »N. F. S. Grundtvig: De Levendes Land«. Poetik IV:1 1971, s. 79-90.

Rønne, K., »Grundtvigs salme: Tør end nogen ihukomme«. Dansk Kirketidende CXXII 1970, s. 68-71.

Rønne, Karl, »Kirke-Klokken«. Dansk Kirketidende CXXII 1970, s. 102-04.

Rønne, K., »Sov sødt, barnlille!« Dansk Kirketidende CXXII 1970, s. 469-71.

Rønne, K., "Skyerne gråne -«. Dansk Kirketidende CXXIII 1971, s. 528-29.

Rønne, Karl, »Rejs op dit hoved, al kristenhed!« Dansk Kirketidende CXXIV 1972, s. 161-63.

Rønne, Karl, „Den gyldne sekvens«. Dansk Kirketidende CXXIV 1972, s. 30102. [Om Grundtvigs danske bearbejdning af den latinske helligåndssalme, nr. 263 i Den danske Salmebog.]

Rønne, Karl, „Bryllupssalmen: 'Det er så yndigt - '«. Dansk Kirketidende CXXV 1973, s. 369-73.

Rønne, K., "Eenligheden«. Dansk Kirketidende CXXV 1973, s. 380-82. [Om »Aftensukket, nattegråden«, nr. 509 i Den danske Salmebog.]

Simon, Erica, »N. F. S. Grundtvig et la France«. I: Rencontres et courants littéraires franco-scandinaves. Actes du $7^{e}$ Congrès International d'Historie des Littératures Scandinaves (Paris 7-12 juillet 1968). Minard, Paris 1972, s. 113-27. (Bibliothèque Nordique, n. sér., 4.) [Tidligere trykt i GrundtvigStudier 1969, s. 7-22.]

Simon, Erica, »Hovedtræk i Grundtvigs kulturfilosofi eller historiesyn«. Højskolebladet 1974 , s. 342-45, 361-64, 377-81, 432-34, 446-48, 477-78, 480-81, 498-501, 516-17, 529-33, 562-66, ... [Oversættelse ved Vilhelm Nielsen af indledningen til E. S.'s franske oversættelse af 1839-afhandlingen »Om Nordens videnskabelige Forening “ (De l'union culturelle du Nord, 1962).]

Thaning, Kaj, „Grundtvigs kirkesyn, med særligt henblik på den danske folkekirkes forhold til staten«. Dansk Kirketidende CXXI 1969, s. 378-82, 390-94.

Thaning, Kaj, "Grundtvigs betydning for Danmark«. Dansk Kirketidende CXXIV 1972, s. 400-04, 412-16. [Sidste kapitel af den u. II ovf. fortegnede engelske/tyske/franske Grundtvig-bog »i forf.s grundtekst«.] 
Thodberg, Christian, „Om Grundtvigs salme 'Herre, hvor skal vi gå hen«. Hymnologiske Meddelelser III 1974, s. 18-30.

Thodberg, Christian, "'Alt står i Guds Faderhånd' og 'Op til Guds hus vi gå'. Belyst ud fra forholdet mellem Grundtvigs prædikener og hans salmer i sommeren 1856«. Dansk Kirkesangs årsskrift 1969-70, 1971, s. 45-62.

Thodberg, Christian, »Prædiken og salme hos Grundtvig, I: 'De Levendes Land' og prædikenerne sommeren 1824; II: Årsskiftet 1839-40 og salmen 'Vor Herre! Til Dig maa jeg tye'«. Dansk Kirkesangs årsskrift 1971-72, 1972, s. $122-55$ og 156-71.

Thomsen, Niels, »Grundtvig og Mao«. Højskolebladet 1972, s. 643-45. [Efterfølges, s. 646-48, af Dea Trier Mørchs og Troels Triers illustrationer til »Et jævnt og muntert, virksomt Liv paa Jord«.]

Vartovbogen 1972. Redigeret af Asta Paulsen, Johs. Birkedal Nielsen og Clemens Barfod. Kirkeligt Samfunds Forlag, København 1972. 150 s. [Indhold bl.a.: N. F. S. Grundtvig, »Prædiken: Dom(inica) Exaudi. Sjette Søndag efter Paaske 1824«, s. 8-16; Johs. Birkedal Nielsen, »Hundrede års grundtvigianisme«, s. 18-27; Erica Simon, »Grundtvigs tanker om folkelighed og Senghors om Négritude«, s. 29-41; Kaj Thaning, »Grundtvig (1872-1972)«, s. 43-62 (foredrag holdt ved det internationale Grundtvig-seminar i Helsingør 13.-19. 8. 1972); Clemens Barfod, "Tradition og tiltale«, s. 69-71 (om salmen "Jesus! hvor er du dog henne? «); Per Fisker, "Brudstykker af et nadversyn«, s. 73-89; Viggo Mortensen, "Om at gøre Grundtvig levende. En kritisk stillingtagen til nogle nyere grundtvigtolkninger«, s. 91-107; Arne Fog Pedersen, »Grundtvigs søndagsgæster«, s. 110-20; Frede Bording, "Aktualiteten i Grundtvigs skoletanker «, s. 141-50.]

Anmeldt af: P[eter] R[iemann] (Dansk Kirketidende CXXIV 1972, s. 559-62).

Vilstrup, Harald, "Fortabelsens æt. Bidrag til fortolkning af et omstridt salmevers«. Hymnologiske Meddelelser II 1973, s. 119-23. [Om »Du, som gaar ud fra den levende Gud «, spec. 6. strofe.]

Vilstrup, Harald, „Op dog Zion! Brorson - Grundtvig«. Hymnologiske Meddelelser II 1973, s. 8-17.

Værge, Johannes, »Den syvende menighed. Et essay om Grundtvig, om ungdomskulturens orientalsk inspirerede nyreligiøsitet og om Jesus-bevægelsen«. Kirke og Kultur LXXVII 1972, s. 522-39.

\section{Avisartikler}

Andersen, Holger, "Hvad var den afgørende linje i Grundtvigs liv? $V e j l e$ Amts Folkeblad 29. 8. 1972.

Andersen, O. Helstrup, »Nu falmer skoven ...«. Jydske Tidende 19.10.1971.

Bredsdorff, Morten, »Var Grundtvig demokrat?« Kristeligt Dagblad (tillæg) 2. 9. 1972.

Christensen, Marie, »Salme-koret ved Grundtvigs jordefærd«. Jydske Tidende 9. 9. 1972.

Christensen, Marie, "Strengen af guld«. Vejle Amts Folkeblad 12. 8. 1972.

Clausen, H. C., »Henrich Steffens skabte Grundtvigs levende ord«. Holstebro Dagblad 24. 4. 1973. 
Frederiksen, Emil, »Forståelse af Grundtvig«. Berlingske Tidende 2. 9. 1972.

Fønss-Jørgensen, Bent, "Tusindtallig skare fulgte Grundtvig til graven på Køge ås«. Dagbladet 2. 9. 1972.

»Grundtvigs 100-års mindedag - historie eller aktuel begivenhed? « Enquetesvar af Jørgen K. Bukdahl, Knud Christensen, Thorbjørn Heick, Johannes Jørgensen og Jørgen Stenbæk. Kristeligt Dagblad (tillæg) 2. 9. 1972.

Hansen, H. P., »Folketingskandidat N.F.S. Grundtvig «. Sjæll. Tidende 11. 8. 1972.

Hedenborg, Max, »Strømme af bøger om Grundtvig«. Dagbladet 31. 8. 1972.

Hvidt. Vald., "Sindssyge eller helligånd«. Kristeligt Dagblad 8.6.1973. [Om sindssygdomsanfaldet/pinseunderet i april 1867, af forf. opfattet som »en karismatisk oplevelse«; se hertil: Jens Højgård, smst. 16. 6. 1973.]

Jensen, Arne Hall, »Grundtvig døde som sol i høst går ned«. Dannevirke 27.7.1972.

Jensen, Th. Borup, »Grundtvig og 'Velkommen igien, Guds Engle smaa'«. Kristeligt Dagblad 23. 12. 1972.

Jessen, Peter Neergaard, "En blomst til Grundtvigs mindekrans«. Vejle Amts Folkeblad 2. 9. 1972. [Prædiken holdt i Thyregod kirke.]

Mortensen, Viggo, »Om at gøre Grundtvig levende«. Information 2. 9. 1972.

Nielsen, Christian, "Kvinder omkring Grundtvig«. Frederiksborg Amts Avis 8. 9. 1972.

Nielsen, Johs. Birkedal, »- da ved man godt, at man skuffer sig selv«. Kristeligt Dagblad 2.9.1972. [Om Grundtvig og EF-problematikken. Hertil Axel Jacobsen, "N. F. S. Grundtvig og EF«, smst. 26. og 27.9. 1972, med svar af J. B. N. 28.9.1972 (»Grundtvig gik ikke i graven med 1900-tallet«) og gensvar af A. J. 2. 10.1972 ("Grundtvig og det 20. århundrede«).]

Rønne, Karl, "De sidste dage og den sidste rejse«. Sjallands Tidende 1.9. 1972.

Rønne, Karl, "Grundtvig og verden«. Sjallands Tidende 14.7.1972. [I anledning af det internationale Grundtvig-seminar i Helsingør 13.-19. 8. 1972.]

Schrøder, Fr., „Grundtvigs måned«. Holbœk Amts Venstreblad 2. 9. 1972.

Stræde, Johs., "Grundtvigs store salmeværk afspejler hans liv - med menneskets oplevelser og spændinger«. Kristeligt Dagblad (tillæg) 2. 9. 1972.

Sørensen, Helge, »Grundtvig som påskedigter«. Flensborg Avis 1. 4. 1971.

Østergaard, Peter, "Bondeblomst fra landsbyhave ...'«. Vejle Amts Folkeblad 28. 3. 1972. [Om »Paaske-Lilien«. - Oprindelig trykt i Aalborg Stiftstidende 11. 4. 1963.]

Østergaard, Peter, „Pinsen i Grundtvigs salmer«. Holbak Amts Venstreblad 19.5. 1972.

Grundtvig-Studier 1971-1973. Udgivet af Grundtvig-Selskabet af 8. September 1947. Under redaktion af Gustav Albeck og William Michelsen. Danske Boghandleres Kommissionsanstalt, København 1971-73. 137, 75, 239 s.

1971) Anmeldt af: Viggo Mortensen (Information 7. 4. 1972), Ejgil Søholm (Jyllands-Posten 29. 4. 1972).

1972) Anmeldt af: P. G. Lindhardt (Jyllands-Posten 15. 11. 1972), Viggo Mortensen (Information 12. 2. 1973).

1973) Anmeldt af: Poul Engberg (Kristeligt Dagblad 13.3. 1974), Jørgen Bang (Aarhuus Stiftstidende 9.5.1974), Viggo Mortensen (Information 2. 8. 1974). 